\title{
Demographic and epidemiological characteristics of HIV opportunistic infections among older adults in Nigeria.
}

\author{
Joshua O Akinyemi ${ }^{1}$, Babatunde O Ogunbosi ${ }^{2}$, Adetona S Fayemiwo ${ }^{3}$, \\ Olubukola A Adesina ${ }^{4}$, Michael Obaro ${ }^{5}$, Modupe A Kuti ${ }^{6}$, Olutosin A Awolude ${ }^{4}$, \\ David O Olaleye ${ }^{7}$, Isaac F Adewole ${ }^{4}$
}

1. Department of Epidemiology and Medical Statistics, College of Medicine, University of Ibadan, Ibadan, Nigeria

2. Department of Paediatrics, College of Medicine, University of Ibadan, Ibadan, Nigeria

3. Department of Medical Microbiology, College of Medicine, University of Ibadan, Ibadan, Nigeria

4. Department of Obstetrics and Gynaecology, College of Medicine, University of Ibadan, Ibadan, Nigeria

5. Department of Pharmacology and Therapeutics, College of Medicine, University of Ibadan, Ibadan, Nigeria

6. Department of Chemical Pathology, College of Medicine, University of Ibadan, Ibadan, Nigeria

7. Department of Virology, College of Medicine, University of Ibadan, Ibadan, Nigeria

\begin{abstract}
Background: In view of the maturing HIV epidemic in sub-Saharan Africa, better understanding of its epidemiology among older adults is necessary in order to design appropriate care and treatment programmes for them.

Objectives: To describe the demographic and epidemiological characteristics of HIV opportunistic infections among newly enrolled patients aged 50 years and above in Ibadan, South-West Nigeria.

Methods: Analysis of data extracted from electronic records of 17, 312 subjects enrolled for HIV/AIDS care and treatment between January 2006 and December 2014 at the ART clinic, University College Hospital, Ibadan.

Results: Age of the patients ranged from 18 to 90 years with a mean of 36.4 years $(\mathrm{SD}=10.3)$ with older adults constituting $12.0 \%$ (2075). Among older adults, about half $(52.9 \%)$ were females. Majority $(59.1 \%)$ were currently married while $25.9 \%$ were widowed. Prevalence of opportunistic infections was 46.6\%. The commonest opportunistic infections (OIs) were: oral candidiasis $(27.6 \%)$, chronic diarrhoea $(23.5 \%$ and peripheral neuropathy $(14.8 \%)$. Significant factors associated with opportunistic infections in older adults were: $\mathrm{CD} 4$ count less than 350 (OR=3.12, CI: 2.29-4.25) and hepatitis $\mathrm{C}$ virus co-infection $(\mathrm{OR}=2.17$, CI: 1.14-4.13).

Conclusion: There is need for prompt response to the peculiar challenges associated with the emerging shift in the epidemiology of HIV and associated infections in sub-Saharan Africa.
\end{abstract}

Keywords: HIV/AIDS, older adults, epidemiological characteristics, opportunistic infections, Nigeria.

DOI: https://dx.doi.org/10.4314/ahs.v17i2.4

Cite as: Akinyemi JO, Ogunbosi BO, Fayemiwo AS, Adesina OA, Obaro M, Kuti MA, Awolude OA, Olaleye DO, Adewole IF. Demographic and epidemiological characteristics of HIV opportunistic infections among older adults in Nigeria. Afri Health Sci. 2017;17(2):315-321. bttps:/ I dx.doi.org/10.4314/abs.v17i2.4

\section{Introduction}

The trend in global HIV epidemic shows that the percentage of persons aged 50 years and over (older adults) living with the virus has been increasing since the past decade $^{1}$. According to the Joint United Nations Programme on HIV/AIDS, as of year 2012, the proportion ranged

\footnotetext{
Corresponding author:

Joshua O Akinyemi, College of Medicine, University of Ibadan, Ibadan, Nigeria

Tel +234-8077677427

Email: odunjoshua@gmail.com
}

from 6\% in Middle East and North Africa to $9 \%$ in sub-Saharan Africa, and 33\% in Western, Central Europe and North America. This phenomenon captioned "aging of the HIV epidemic" has been attributed to three factors: (i) increased life expectancy gained from antiretroviral therapy, (ii) decreased HIV incidence in younger adults, and (iii) latent risky sexual behaviours among older adults ${ }^{1}$.

One daunting challenge to a clear understanding of the features of the disease in this population is the relativepaucity of data on HIV prevalence and sexual behaviour among older adults especially in sub-Saharan Africa (SSA). The Demographic and Health Surveys (DHS) which is the main source of such data in the SSA region 
are conducted among women aged 15-49 years and men aged 15-59 years. Thus, even if HIV sero-prevalence was to be estimated for countries that include HIV testing in the surveys, it is an impossible task to derive estimate for women aged 50 years and above. Very few countries such as South Africa ${ }^{2}$, and Kenya ${ }^{3}$ have conducted national HIV survey from which prevalence among older adults has been provided. For instance, the 2014 South African survey revealed that the prevalence among persons aged 50-54 years was 13\% compared to $18 \%$ in age $15-49$ years ${ }^{2}$. Negin et al extrapolated HIV prevalence from existing UNAIDS estimates for several sub-Saharan African (SSA) countries as part of an effort to generate the much needed data for this special group ${ }^{4}$. The results suggested that overall prevalence of HIV in older adults was $4.0 \%$ compared to $5.0 \%$ in $15-49$ years. The findings further showed that Nigeria and four other countries (Mozambique, South Africa, Zambia and Zimbabwe) have 54\% of the total number of older adults living with HIV in $\mathrm{SSA}^{4}$. Recent data from HIV counseling and testing centre at a teaching hospital in South Eastern Nigeria reported a prevalence of $8.2 \%$ among older adults ${ }^{5}$.

While HIV prevention programmes inadvertently exclude older adults (especially women), evidence from behavioural surveys in SSA point to the fact that risky sexual behaviours are prevalent coupled with poor knowledge of HIV transmission and prevention ${ }^{6}$. These emerging challenges have implications for HIV prevention, care and treatment programs. Incidence of HIV infection might have been as high among older adults as it was among youths but the picture was unclear because they have been more or less neglected in HIV testing and prevention programmes ${ }^{6}$.

Most of the current knowledge about the characteristics of HIV infection in older persons has come from the developed countries in North America ${ }^{7,8}$ and Europe ${ }^{9-11}$. The pattern has also been described in China ${ }^{12,13}$ and Taiwan ${ }^{14}$. Many of these studies suggested that older and younger adults differ in terms of epidemiological and clinical features of HIV infection, response to ART and post-diagnosis survival. Heterosexual contact was the most common HIV risk factor reported among older adults ${ }^{9,12}$. In addition, they have lower CD4 counts, higher prevalence of opportunistic infections, and more likely to be at an advanced stage of HIV/AIDS at first presentation ${ }^{10,11,13}$. As expected, this poor health status at presentation predisposes older adults to faster disease progression, poor treatment success and higher mortality. Metallides et al also reported higher prevalence of cardiovascular and neurological conditions among older adults, though these are health conditions associated with old age?

Sub-Saharan Africa is lagging behind in terms of literature on the characteristics of HIV infection in older adults. Negin et al found that $29.6 \%$ of persons aged 50 years and above in South Africa had two or more chronic diseases compared to $8.8 \%$ in age group 18-49 years $^{15}$. Meanwhile, Nyirenda et al showed that older adults in Uganda and South Africa had poorer emotional and functional wellbeing ${ }^{16}$. A review article also suggested that older Africans living with HIV have unique clinical manifestations different from those in developed countries ${ }^{17}$. In the meantime, model projections by Hotelez et al showed that the proportion of older adults with HIV in SSA will continue to rise to peak at $25 \%$ in the year $2040^{18}$. In view of this imminent burden, it is necessary to provide additional data on the epidemiology of HIV infection in older adults in the continent so that appropriate suggestions can be made for care and treatment programs. Therefore, this study describes the demographic and epidemiological characteristics of HIV infection among newly enrolled patients aged 50 years and above at the University College Hospital, Ibadan in South West Nigeria.

\section{Methods \\ Study setting}

This study was conducted among newly enrolled HIV/ AIDS clients at the anti-retroviral cinic (ART) of the University College Hospital (UCH)/ College of Medicine, Ibadan, South-West Nigeria. The ART clinic at the UCH Ibadan was one of the first twenty five ART sites established by the Federal Government of Nigeria in 2002 to provide anti-retroviral drugs to HIV/AIDS patients. Thereafter, treatment at the clinic has been supported by President's Emergency Plan for AIDS Relief (PEPFAR) and AIDS Prevention Initiative in Nigeria (APIN). Patients recruitment, care, treatment and follow up procedures at the clinic have been described in a previous report ${ }^{19}$.

\section{Study design}

This study was a secondary analysis of data extracted from electronic records of 17,312 subjects enrolled for HIV/AIDS care and treatment between January 2006 
and December 2014 at the ART clinic, University College Hospital, Ibadan, Nigeria. Of this number, 2,075 were aged 50 years and above.

\section{Data management and analysis}

Variables extracted included socio-demographic characteristics, baseline opportunistic infections, CD4 counts, viral load, hepatitis $\mathrm{B}$ and $\mathrm{C}$ status. Continuous variables were presented as mean and standard deviation while categorical variables were presented as frequencies / percentages. The Chi square test was employed to investigate homogeneity in the demographic and clinical characteristics between younger ( $<50$ years) and older patients $(>=50$ years). Student's t-test and Mann-Whitney test (for non-normally distributed variables) was used to test for significant difference in mean values between the two groups. Stratified multiple logistic regression analysis was done to explore the epidemiological characteristics of opportunistic infections among younger patients, older patients and the total cohort. P-values less than 0.05 were considered statistically significant. Results were presented for older persons and those younger than 50 years in order to document differences in the characteristics of the two groups. For emphasis and in line with the study ob-

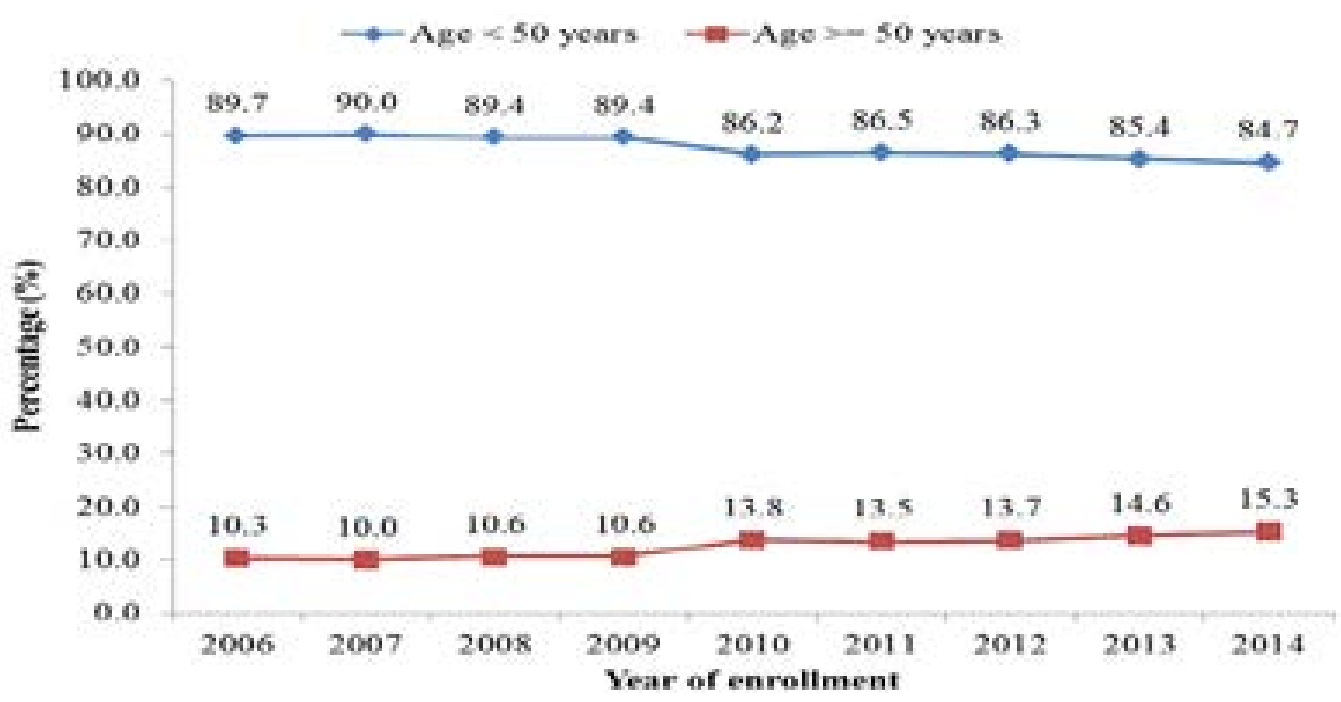

Figure 1: Trends in the percentage of older and younger patients at ART Clinic, UCH, Ibadan, Nigeria (2006-2014)

Although subsequent analyses involved both young and older patients, results are presented for the older persons only. Their background characteristics are presented in Table 1.

About half $(52.9 \%)$ were females. The distribution of their marital status revealed that $59.1 \%$ were married jective, only the results for older persons were described and discussed.

\section{Ethical considerations}

The anti-retroviral treatment program was approved by the University of Ibadan/University College Hospital Ibadan Joint Institutional Review Board (approval number-UI/IRC/04/0070). Informed consent forms were signed by all patients during enrollment procedures and included consent for data repository and use at later dates. The electronic medical record systems for the patient data is implemented on a password-protected computer system for the purpose of privacy and confidentiality of data. Patients' folders containing case report forms were kept in safe cabinets with locks in the medical records section where access is restricted to authorised persons only. The data was de-identified before analysis.

\section{Results}

\section{Demographic characteristics}

The age of the patients ranged from 18 to 90 years with a mean of $36.4(\mathrm{SD}=10.3)$ years. Out of the total number of records, $2075(12.0 \%)$ were aged 50 years and above Figure 1 shows that the percentage of older patients increased from $10.3 \%$ in 2006 to $13.8 \%$ in 2010 and $15.3 \%$ in $2014(\mathrm{p}<0.001)$. 
Table 1: Demographic characteristics of patients at the ART clinic of UCH, Ibadan, Nigeria (2006-2014)

\begin{tabular}{|c|c|c|c|c|c|}
\hline Variables & $\begin{array}{l}\text { Aged }<\mathbf{5 0} \\
\text { years }\end{array}$ & $\begin{array}{l}\text { Aged }>=\mathbf{5 0} \\
\text { years }\end{array}$ & All patients & $\begin{array}{l}\text { Chi } \\
\text { square }^{+}\end{array}$ & p-value \\
\hline & $\mathrm{n}=15,237$ & $\mathrm{n}=2,075$ & $\mathrm{n}=17,312$ & & \\
\hline Sex & $\%$ & $\%$ & $\%$ & & \\
\hline Male & 29.8 & 47.1 & 31.9 & & \\
\hline Female & 70.2 & 52.9 & 68.1 & 251.923 & $<0.001$ \\
\hline \multicolumn{6}{|l|}{ Marital Status } \\
\hline Single & 18.1 & 2.5 & 16.3 & & \\
\hline Married & 63.1 & 59.1 & 62.6 & & \\
\hline Divorced/separated & 10.1 & 12.5 & 10.4 & & \\
\hline Widowed & 8.7 & 25.9 & 10.8 & 789.53 & $<0.001$ \\
\hline \multicolumn{6}{|l|}{ Education } \\
\hline None & 10 & 28.3 & 12.1 & & \\
\hline Primary & 26.7 & 31 & 27.2 & & \\
\hline Secondary & 38.9 & 20.8 & 36.7 & & \\
\hline Tertiary & 24.5 & 20 & 23.9 & 672.76 & $<0.001$ \\
\hline \multicolumn{6}{|l|}{ HIV risk factors } \\
\hline Heterosexual & 91.1 & 89.4 & 90.9 & 6.41 & 0.011 \\
\hline $\begin{array}{l}\text { Intravenous drug } \\
\text { use }\end{array}$ & 0.1 & 0.0 & 0.1 & 0.31 & 0.577 \\
\hline MSM & $24(0.2)$ & $3(0.1)$ & $27(0.2)$ & 0.02 & 0.889 \\
\hline Blood transfusion & $385(2.5)$ & $54(2.4)$ & $439(2.5)$ & 0.042 & 0.837 \\
\hline Unknown & $521(3.4)$ & $97(4.7)$ & $618(3.6)$ & 8.36 & 0.004 \\
\hline
\end{tabular}

Epidemiological characteristics of opportunistic infections

The prevalence of HIV-related and other diagnoses are summarised in Table 2. The overall prevalence of opportunistic infections among the older patients was $46.6 \%$.
Among the specific diagnosis, candida (27.6\%) and chronic diarrhoea $(23.5 \%)$ were the most common. Others include peripheral neuropathy $(14.8 \%)$ and chronic dermatitis $(12.9 \%)$. The prevalence of hepatitis B and $\mathrm{C}$ was $7.8 \%$ and $3.5 \%$ respectively. The median baseline CD4 count was 177 cells $/ \mathrm{mm}^{3}$.

Table 2: Epidemiological characteristics of HIV-related infections among patients at the ART clinic of UCH, Ibadan, Nigeria (2006-2014)

\begin{tabular}{|c|c|c|c|c|c|}
\hline HIV-related diagnosis & $\begin{array}{l}\text { Aged }<\mathbf{5 0} \\
\text { years }\end{array}$ & $\begin{array}{l}\text { Aged }>= \\
50 \text { years }\end{array}$ & All patients & $\begin{array}{l}\text { Chi } \\
\text { square }\end{array}$ & p-value \\
\hline & $\mathrm{n}=15,237$ & $\mathrm{n}=2,075$ & $\mathrm{n}=17,312$ & & \\
\hline Pulmonary tuberculosis & $780(5.1)$ & $136(6.6)$ & $916(5.5)$ & 7.51 & 0.006 \\
\hline Candida & $3773(24.8)$ & $573(27.6)$ & $4346(25.1)$ & 7.9 & 0.005 \\
\hline Chronic dermatitis & $1646(10.8)$ & 268 (12.9) & $1914(11.1)$ & 8.29 & 0.004 \\
\hline Chronic Diarrhea & $2221(18.3)$ & $375(23.5)$ & $2596(18.9)$ & 25.09 & $\mathrm{p}<0.001$ \\
\hline Genital ulcer & $464(3.0)$ & $50(2.0)$ & $514(3.0)$ & 2.56 & 0.11 \\
\hline Herpes simplex & $149(1.0)$ & $23(1.1)$ & $172(1.0)$ & 0.32 & 0.574 \\
\hline Herpes Zoster & $300(2.0)$ & $78(3.8)$ & $378(2.2)$ & 27.4 & $\mathrm{p}<0.001$ \\
\hline Peripheral neuropathy & $1701(11.2)$ & $307(14.8)$ & $2008(11.6)$ & 23.49 & $\mathrm{p}<0.001$ \\
\hline $\mathrm{PCP}$ & $182(1.2)$ & $26(1.3)$ & $208(1.2)$ & 0.05 & 0.818 \\
\hline Wasting syndrome & 2417 (15.9) & $418(20.1)$ & 2835 (16.4) & & \\
\hline Opportunistic infections & $5999(39.4)$ & $967(46.6)$ & $6966(40.2)$ & 39.71 & $\mathrm{p}<0.001$ \\
\hline \multicolumn{6}{|l|}{ Other diagnosis } \\
\hline Hypertension & $225(1.5)$ & $128(6.2)$ & $353(2.0)$ & 201.28 & $\mathrm{p}<0.001$ \\
\hline Renal disease & $48(0.3)$ & $15(0.7)$ & $63(0.4)$ & 8.38 & 0.004 \\
\hline Hx of Alcohol use & $1748(11.5)$ & $293(14.1)$ & $2041(11.8)$ & 12.32 & $\mathrm{p}<0.001$ \\
\hline $\begin{array}{l}\text { Hepatitis B surface } \\
\text { antigen }\end{array}$ & $1568(12.2)$ & $137(7.8)$ & $1705(11.6)$ & 29.3 & $\mathrm{p}<0.001$ \\
\hline Hepatitis C & $432(3.4)$ & $60(3.5)$ & $492(3.4)$ & 0.017 & 0.897 \\
\hline $\begin{array}{l}\text { Log10 RNA Viral load: } \\
\text { Mean(SD) }\end{array}$ & $4.66(1.18)$ & $\begin{array}{l}4.79 \\
(1.24)\end{array}$ & $4.68(1.18)$ & $\mathrm{T}=4.179$ & $\mathrm{p}<0.001$ \\
\hline Median CD4 count & 203 & 177 & 199 & $\mathrm{MW}=18.48$ & $\mathrm{p}<0.001$ \\
\hline
\end{tabular}

T student's t-test statistic; MW: Mann-Whitney test statistic 
Factors associated with baseline opportunistic infections

The results of multiple logistic regression models fitted to determine the independent factors associated with opportunistic infections (OIs) in older patients are present- ed in Table 3. Demographic variables (sex, marital status and education) were not associated with opportunistic infections. the significant factors were CD4 count less than $350(\mathrm{OR}=3.12, \mathrm{CI}: 2.29-4.25)$ and hepatits $\mathrm{C}$ virus infection $(\mathrm{OR}=2.17, \mathrm{CI}: 1.14-4.13)$.

Table 3: Adjusted Odds Ratio for demographic and clinical variables associated with Baseline Opportunistic infections in Younger and Older Adult HIV patients

\begin{tabular}{|c|c|c|c|}
\hline Variables & Aged $<50$ years & Aged $>=50$ years & All patients \\
\hline & OR $(95 \% \mathrm{CI})$ & OR $(95 \% \mathrm{CI})$ & OR $(95 \% \mathrm{CI})$ \\
\hline \multicolumn{4}{|l|}{ Sex } \\
\hline Male & 1.00 & 1.00 & 1 \\
\hline Female & $0.69(0.62-0.76)^{*}$ & $0.93(0.72-1.21)$ & $0.72(0.66-0.79)^{*}$ \\
\hline \multicolumn{4}{|l|}{ Marital Status } \\
\hline Single & 1.00 & 1.00 & 1 \\
\hline Married & $0.86(0.75-0.97) *$ & $0.62(0.19-1.98)$ & $0.89(0.78-0.99)^{*}$ \\
\hline Divorced/separated & $1.63(1.37-1.94)^{*}$ & $1.05(0.32-3.47)$ & $1.59(1.35-1.87)^{*}$ \\
\hline Widowed & $1.22(1.03-1.47)^{*}$ & $0.90(0.28-2.96)$ & $1.22(1.04-1.44)^{*}$ \\
\hline \multicolumn{4}{|l|}{ Education } \\
\hline None & 1.00 & 1.00 & 1 \\
\hline Primary & $1.19(1.01-1.40)^{*}$ & $1.07(0.79-1.45)$ & $1.15(0.99-1.32)$ \\
\hline Secondary & $1.01(0.86-1.18)$ & $0.89(0.63-1.25)$ & $0.96(0.84-1.11)$ \\
\hline Tertiary & $0.78(0.66-0.92)^{*}$ & $0.72(0.50-1.04)$ & $0.74(0.63-0.85)^{*}$ \\
\hline Log10 RNA Viral load & $1.36(1.30-1.41)^{*}$ & $1.07(0.96-1.19)$ & $1.31(1.26-1.36)^{*}$ \\
\hline CD4 count $<350$ & $2.75(2.47-3.07)^{*}$ & $3.12(2.29-4.25)^{*}$ & $2.79(2.52-3.09)^{*}$ \\
\hline HbSAg & $1.23(1.08-1.40)^{*}$ & $1.06(0.69-1.63)$ & $1.22(1.08-1.37)^{*}$ \\
\hline HCV & $1.34(1.07-1.69) *$ & $2.17(1.14-4.13) *$ & $1.43(1.16-1.76)^{*}$ \\
\hline
\end{tabular}

$* \mathrm{p}<0.05$

\section{Discussion}

Increased coverage of anti-retroviral therapy in sub-Saharan Africa is projected to affect the age structure of HIV epidemic thereby resulting in larger proportion of older adults ${ }^{18}$. The multiplier effects of this unfolding age structure have implications for social support and health systems. Health systems need to be abreast with the challenges and plan adequately for the peculiar healthcare needs of these older persons. An understanding of the epidemiology of HIV infection among older adults is necessary in order to design appropriate care and treatment guidelines required to guarantee good quality of life. This study provides data on the epidemiological characteristics of HIV infection among older adults in Nigeria.

The results showed that among newly enrolled HIV-infected persons in almost a decade, more than 1 out of every ten is an older adult. This proportion is similar to that reported in $\mathrm{USA}^{7}$ and in a multi-centre study conducted in 9 SSA countries ${ }^{20}$ but lower than $22.5 \%$ reported from Eastern China ${ }^{12}$. The higher proportion in the Chinese may be explained by the peculiar demographic and epidemiological features of the Zhejiang province where the study was conducted. Prevalence of sexually transmitted infections was high due to risky sexual practices especially among tourists and migrants from different parts of the country $^{12}$.

We found that the proportion of older adults has increased steadily between 2009 and 2014. The rise in percentage of older adults may be due to new infections in this population or recent diagnosis of persons who have been infected long before they reached older adulthood. It may also be explained by late manifestation of symptoms, usually at advanced stages, prompting the need to seek health care. Some studies have suggested that risky sexual behaviour is also common in this age group and as a result, new infections could be going on undetected until symptoms begin to appear ${ }^{21}$. With the availability of ART, the population of older adults with HIV is bound to increase. It is therefore necessary to anticipate this upsurge and make proper plans for the healthcare and treatment needs of this sub-population. 
The gender distribution among older adults was almost balanced between males (47\%) and females (53\%) unlike the younger age group in which females constituted about two-thirds. The reasons for this are not very obvious because even if mortality were to be considered, it is higher among males. This finding may be an indication of on-going new infections in older adults at a rate higher among men than women. Evidence from qualitative data among older adults in SouthWestern Nigeria showed that sexual relationships persist till older age and men are believed to be naturally polygynous in Africa ${ }^{22,23}$. HIV surveillance and prevention activities need to be extended to older adults apart from the current focus on youth and persons in reproductive age.

Opportunistic infections such as tuberculosis, oral candidasis, chronic dermatitis, chronic diarrhoea diseases, and herpes zoster were prevalent among older adults. As expected, the same trend applies to non-communicable diseases such as hypertension and renal disease. These results confirmed the differences in the epidemiological characteristics with respect to OIs and co-morbidities in HIV-infected older adults ${ }^{11-14,21}$. Apart from possible low immunity in older ages, a higher prevelance of opportunistic infections in newly enrolled older adults with HIV may be an indication of late presentation and advanced stage of infection. Older adults are rarely diagnosed with HIV via routine counselling and testing because of their unwillingness to test voluntarily. Besides, testing facilities are usually patronised mostly by youth and women of reproductive age because HIV prevention activities are concentrated among them. As long as there are no manifest symptoms, HIV infected older adults may not present for voluntary HIV counselling and testing. HIV prevention, testing and counselling programmes need to adopt newer strategies to reach this population group. Besides, in order to slow down the progression to AIDS and poorer outcomes among older HIV patients, early commencement of ART might be necessary.

Results from the multivariate analysis showed that only CD4 count and hepatitis $\mathrm{C}$ virus infection co-infection were the significant factors in older adults. This epidemiological pattern has implication for survival and other treatment outcomes such as viral suppression and immunological response. A previous study at the same health facility showed that the risk of early mortality (within

African Health Sciences Vol 17 Issue 2, June, 2017
6 months of enrollment) was 32\% higher among older adults ${ }^{19}$. The effect of these factors on treatment outcome (immunological and viral response) requires further evaluation.

\section{Strength and limitations}

This study explored an area of discourse that will continue to generate further investigations especially given the fact that anti-retroviral treatment is lifelong; as well as the unfolding demographic and epidemiological transitions in developing countries. The limitations of this study emanate from the fact that routine electronic medical records were analysed. For instance, the electronic records do not contain data on other variables such as sexual behaviour, drug use, and health seeking behaviour. Some of these factors could have shed more light on the characteristics of older adults living with HIV in SouthWest Nigeria.

\section{Conclusion}

The proportion of older adults among HIV-infected persons in SouthWest Nigeria is increasing. The prevalence of opportunistic infections is very high and associated with baseline CD4 count and hepatitis C co-infection. HIV prevention, care and treatment programmes should provide timely response to the peculiar challenges associated with this trend.

\section{Acknowledgements}

We acknowledge the Government of Nigeria, PEPFAR, CDC and AIDS Prevention Initiative in Nigeria for funding patients' care and treatment at UCH, Ibadan. Our appreciation also goes to the hardworking clinic staff that generated the routine data analysed in this study.

\section{Conflict of interest disclosure}

The authors declare that potential conflict of interest does not exist.

\section{References}

1. UNAIDS. HIV and Aging. Geneva, Switzerland: UNAIDS, 2013.

2. Shisana O, Rehle T, Simbayi LC, et al. South African National HIV Prevalence, Incidence and Behaviour Survey, 2012. Cape Town: Human Sciences Research Council, 2014.

3. Ministry of Health [Kenya]. AIDS Indicator Survey. Nairobi: Ministry of Health, 2007.

4. Negin J, Cumming RG. HIV infection in older adults 
in sub-Saharan Africa: extrapolating prevalence from existing data. Bull World Health Organ. 2010;88(11):847-853.

5. Stephen OK, Ngozi O, Prince UE, et al. HIV Infection among 50 Years and above Attending HIV Counseling and Testing (HCT) in Nnewi, Nigeria. World Journal of AIDS. 2015;4:93-98.

6. Negin J, Nemser B, Cumming R, et al. HIV attitudes, awareness and testing among older adults in Africa. AIDS Behav. 2012;16(1):63 PubMed -68.

7. Chiao EY, Ries KM, Sande MA. AIDS and the Elderly. Clinical Infectious Diseases. 1999;28:740-745.

8. Sankar A, Nevedal A, Neufeld S, et al. What do we know about older adults and HIV? A review of social and behavioral literature. AIDS Care. 2011;23(10):1187 PubMed -1207.

9. Metallidis S, Tsachouridou O, Skoura L, et al. Older HIV-infected patients-an underestimated population in Northern Greece: epidemiology, risk of disease progression and death. Int J Infect Dis. 2013;17(10): PubMed e883891.

10. Nogueras M, Navarro G, Anton E, et al. Epidemiological and clinical features, response to HAART, and survival in HIV-infected patients diagnosed at the age of 50 or more. BMC Infect Dis. 2006;6:159.

11. Orchi N, Balzano R, Scognamiglio P, et al. Ageing with HIV: newly diagnosed older adults in Italy. AIDS Care. 2008;20(4):419-425.

12. Xie T, Wu N. Epidemiological and mortality analysis of older adults with HIV in Eastern China. Clin Interv Aging. 2013;8:1519-1525 PubMed.

13. Zhang Y, Fuller-Thomson E, Mitchell CA, et al. Older adults with HIV/AIDS in rural China. The Open AIDS Journal. 2013;7:51-57.

14. Kang SC, Hwang SJ, Wong WW. Characteristics of human immunodeficiency virus infections among the elderly in Taiwan: a nationwide study. J Chin Med Assoc. 2011;74(5):215 PubMed -219.

15. Negin J, Martiniuk A, Cumming RG, et al. Prevalence of HIV and chronic comorbidities among older adults. AIDS. 2012;26 Suppl 1:S55-63.

16. Nyirenda M, Newell ML, Mugisha J, et al. Health, wellbeing, and disability among older people infected or affected by HIV in Uganda and South Africa. Glob Health Action. 2013;6:19201.

17. Bendavid E, Ford N, Mills EJ. HIV and Africa's elderly: the problems and possibilities. AIDS. 2012;26 Suppl 1:S85-91.

18. Hontelez JA, de Vlas SJ, Baltussen R, et al. The impact of antiretroviral treatment on the age composition of the HIV epidemic in sub-Saharan Africa. AIDS. 2012;26 Suppl 1:S19-30.

19. Akinyemi JO, Adesina OA, Kuti MO, et al. Temporal distribution of baseline characteristics and association with early mortality among HIV-positive patients at University College Hospital, Ibadan, Nigeria. African Journal of AIDS Research. 2015;14(3):201-2017.

20. Greig J, Casas EC, O'Brien DP, et al. Association between older age and adverse outcomes on antiretroviral therapy: a cohort analysis of programme data from nine countries. AIDS. 2012;26 Suppl 1:S31-37.

21. Nguyen N, Holodniy M. HIV infection in the elderly. Clin Interv Aging. 2008;3(3):453 PubMed -472.

22. Agunbiade OM, Ayotunde T. Ageing, sexuality and enhancement among Yoruba people in South Western Nigeria. Cult Health Sex. 2012;14(6):705 PubMed -717.

23. Orubuloye IO, Caldwell JC, Caldwell P. Perceived male sexual needs and male sexual behaviour in SouthWest Nigeria. Soc Sci Med. 1997;44(8):1195 PubMed -1207. 